\title{
Reactive-oxygen-species-mediated mechanism for photoinduced antibacterial and antiviral activities of $\mathrm{Ag}_{3} \mathrm{PO}_{4}$
}

Youngsik Seo ${ }^{1}$, Keunchun Park', Yonggun Hong ${ }^{2}$, Eun Sik Lee ${ }^{3}$, Sang-Soon Kim², Yong-Tae Jung ${ }^{3}$, Heonyong Park', Chian Kwon', Young-Sik Cho ${ }^{4}$ and Young-Duk Huh ${ }^{4 *}$

\begin{abstract}
Cubic-shaped $\mathrm{Ag}_{3} \mathrm{PO}_{4}$ crystals with a mean size of $1 \mu \mathrm{m}$ were synthesized by a precipitation method from a mixed solution of $\mathrm{AgNO}_{3}, \mathrm{Na}_{2} \mathrm{HPO}_{4}$, and triethanolamine. The antibacterial activities against Escherichia coli, Listeria innocua, and Pseudomonas syringae DC3000 in both the absence and presence of $\mathrm{Ag}_{3} \mathrm{PO}_{4}$ under dark conditions and in the presence of $\mathrm{Ag}_{3} \mathrm{PO}_{4}$ under red-light $(625 \mathrm{~nm})$ and blue-light $(460 \mathrm{~nm})$ irradiation were examined. The concentrations of reactive oxygen species (ROS) were also measured in the antibacterial action of the $\mathrm{Ag}_{3} \mathrm{PO}_{4}$ against Escherichia coli. The photoinduced enhancement of the $\mathrm{Ag}_{3} \mathrm{PO}_{4}$ antibacterial activity under blue-light irradiation is explained by the formation of ROS during the antibacterial action of the $\mathrm{Ag}_{3} \mathrm{PO}_{4}$. Moreover, the antiviral activity of $\mathrm{Ag}_{3} \mathrm{PO}_{4}$ against amphotropic $10 \mathrm{~A} 1$ murine leukemia virus enhanced under blue-light irradiation via ROS production. These results provide an insight into extended bio-applications of $\mathrm{Ag}_{3} \mathrm{PO}_{4}$.
\end{abstract}

Keywords: Reactive oxygen species, Photoenhanced antibacterial activities, Antiviral activity, $\mathrm{Ag}_{3} \mathrm{PO}_{4}$

\section{Introduction}

Photoenhanced catalytic and antibacterial materials have been extensively investigated in efforts to eliminate organic pollutants and microorganisms from wastewater (Chatterjee and Dasgupta 2005; Lapworth et al. 2012; Mouele et al. 2015; Schwarzenbach et al. 2006). In the process where electrons from the conduction band recombine with holes from the valence band of photocatalytic materials, reactive oxygen species (ROS) such as superoxide anions $\left(\mathrm{O}_{2}{ }^{--}\right)$, hydroxyl radicals $(\cdot \mathrm{OH})$, and singlet oxygen $\left({ }^{1} \mathrm{O}_{2}\right)$ are produced (Dickinson and Chang 2011; Li et al. 2012). These ROS play an important role in the photoenhanced catalytic activities. The ROS can also damage biomolecules and regulate cell death of microorganisms (Du and Gebicki 2004; Overmyer et al. 2003).

\footnotetext{
* Correspondence: ydhuh@dankook.ac.kr

${ }^{4}$ Department of Chemistry, Dankook University, Cheonan 31116, Republic of Korea

Full list of author information is available at the end of the article
}

Silver phosphate $\left(\mathrm{Ag}_{3} \mathrm{PO}_{4}\right)$, which has an indirect bandgap of $2.36 \mathrm{eV}$, exhibits excellent photoenhanced catalytic activity, with a quantum efficiency as high as $90 \%$ under irradiation at $420 \mathrm{~nm}$ (Bi et al. 2011; Chen et al. 2015). $\mathrm{Ag}_{3} \mathrm{PO}_{4}$ exhibits higher photocatalytic activity than $\mathrm{TiO}_{2}$ in the degradation of organic dyes such as methylene blue and rhodamine B (Dong et al. 2014; Liang et al. 2012). The antibacterial activity and photoinduced antibacterial activity of $\mathrm{Ag}_{3} \mathrm{PO}_{4}$ have also been investigated (Buckley et al. 2010; Piccirillo et al. 2015; Seo et al. 2017; Suwanprateeb et al. 2012; Wu et al. 2013). However, to the best of our knowledge, there is no report that examines antibacterial or antiviral activities arising from the ROS photoinducibly generated by $\mathrm{Ag}_{3} \mathrm{PO}_{4}$. In this work, we assessed the role of ROSmediated behavior in the photoinduced antibacterial and antiviral activities of $\mathrm{Ag}_{3} \mathrm{PO}_{4}$ crystals against various bacteria and amphotropic 10A1 murine leukemia virus (MLV), respectively. 


\section{Methods/experimental}

\section{Synthesis of $\mathrm{Ag}_{3} \mathrm{PO}_{4}$ microcrystal}

$\mathrm{AgNO}_{3}$ (99\%, Aldrich), $\mathrm{Na}_{2} \mathrm{HPO}_{4}$ (99\%, Aldrich), and triethanolamine (TEA; 98\%, Aldrich) were used without further purification. $\mathrm{Ag}_{3} \mathrm{PO}_{4}$ was synthesized via a simple precipitation method at room temperature. Six milliliters of $1.0 \mathrm{M}$ TEA aqueous solution was added to 30 $\mathrm{mL}$ of $0.01 \mathrm{M} \mathrm{AgNO}_{3}$ aqueous solution with stirring at room temperature for $10 \mathrm{~min}$. Then, $20 \mathrm{~mL}$ of $5 \mathrm{mM}$ $\mathrm{Na}_{2} \mathrm{HPO}_{4}$ aqueous solution was added, and the resulting mixture was stirred for $1 \mathrm{~min}$ at room temperature. The product was collected by centrifugation at $4000 \mathrm{rpm}$ for $5 \mathrm{~min}$, washed several times with water and ethanol, and then dried for $24 \mathrm{~h}$ at room temperature.

\section{Antibacterial and antiviral experimental conditions}

A small fraction $(10 \mu \mathrm{L})$ of Escherichia coli $(E$. coli) overnight culture was added evenly to fresh $5 \mathrm{~mL}$ Luria-Bertani (LB) medium containing $2 \mu \mathrm{g} / \mathrm{mL}$ of the $\mathrm{Ag}_{3} \mathrm{PO}_{4}$ product with or without $1 \mathrm{mM} \mathrm{N}$-acetylcysteine (NAC, Aldrich) and then incubated in a $37^{\circ} \mathrm{C}$ shaking incubator. Pseudomonas syringae (P. syringae) DC3000 was grown at $28{ }^{\circ} \mathrm{C}$ in NYGB medium (0.5\% tryptone, $3 \%$ yeast extract, and $2 \%$ glycerol) containing rifampicin. Two-day grown P. syringae DC3000 culture was evenly aliquoted into $10 \mathrm{~mL}$ fresh NYGB medium containing rifampicin and further grown at $28^{\circ} \mathrm{C}$.

Antibacterial activity of $\mathrm{Ag}_{3} \mathrm{PO}_{4}$ to Listeria innocua ( $L$. innocua), which was used as L. monocytogenes surrogate, was measured using the agar-overlay method. Bacterial culture incubated in tryptic soy broth (TSB) was inoculated to tryptic soy agar (TSA) or TSA containing $\mathrm{Ag}_{3} \mathrm{PO}_{4}(4 \mu \mathrm{g} / \mathrm{mL})$. Oxford agar base (OAB; Difco, Sparks, MD) with antimicrobial supplement (Bacto Oxford antimicrobial supplement; Difco) was poured into 50-mm petri dish (bottom agar), overlaid with the inoculated TSA (top agar), and incubated at $37^{\circ} \mathrm{C}$ with or without light treatment. After incubation at $37^{\circ} \mathrm{C}$ for 22 $\mathrm{h}, \mathrm{OAB}$ images were obtained and typical black colonies were enumerated.

For virus production, 293T human embryonic kidney cells (ATCC CRL-11268) were transiently transfected with a full-length molecular clone pMoMLV-10A1EGFP using the CalPhos Mammalian Transfection Kit (TaKaRa Bio, Shiga, Japan). pMoMLV-10A1-EGFP is a replication-competent retroviral vector containing enhanced green fluorescent protein (EGFP). To determine the viral titer, $1 \mathrm{~mL}$ of virus-containing supernatants and $2 \mu \mathrm{g} / \mathrm{mL} \mathrm{Ag}_{3} \mathrm{PO}_{4}$ were mixed at $37^{\circ} \mathrm{C}$ for different irradiation time under the blue and red light sources. HT1080 human fibrosarcoma cells (ATCC CCL-121) were infected with $1 \mathrm{~mL}$ of viral supernatants at a multiplicity of infection (MOI) of 1 in the presence of $8 \mu \mathrm{g} /$ $\mathrm{mL}$ polybrene. Two days after infection, green fluorescent protein (GFP)-positive cells were analyzed by a FACSCalibur ${ }^{\mathrm{TM}}$ flow cytometer (Becton, Dickinson and Company, Franklin Lakes, NJ, USA).

Intracellular amounts of ROS were analyzed by fluorescence spectroscopy after reaction with $2^{\prime}, 7^{\prime}$-dichlorodihydrofluorescein diacetate (DCFH-DA). Briefly, E. coli cells were treated with or without $\mathrm{Ag}_{3} \mathrm{PO}_{4}$ under light irradiation. The cells were then additionally incubated with phosphate-buffered saline (PBS) containing $500 \mu \mathrm{M}$ DCFH-DA for $1 \mathrm{~h}$ at room temperature in the dark. Finally, the amounts of ROS were measured by fluorescence spectrophotometry (Synergy HTX multimode reader; $\lambda_{\mathrm{ex}}=485 \pm 20 \mathrm{~nm}, \lambda_{\mathrm{em}}=528 \pm 20 \mathrm{~nm}$ ). To obtain $E$. coli images, we placed DCFH-DA-stained cells on a slide glass, covered them with a cover slip, and then observed them by fluorescence microscopy (Axioplan 2 microscope) using a green filter.

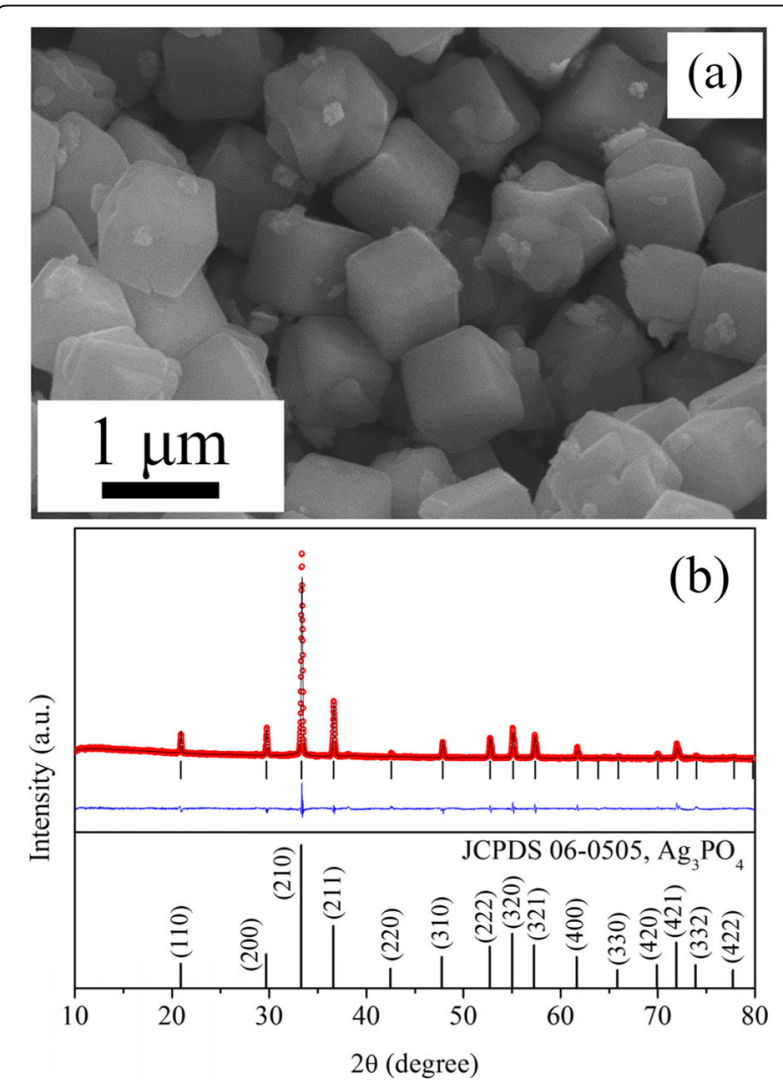

Fig. 1 a SEM images of the as-synthesized $\mathrm{Ag}_{3} \mathrm{PO}_{4}$ product prepared by the precipitation method. $\mathbf{b}$ (Top panel) XRD patterns of the $\mathrm{Ag}_{3} \mathrm{PO}_{4}$ product, along with the patterns calculated using the Rietveld refinement method; the solid line (black) and open circles (red) present the measured and calculated XRD data, respectively. The intensity differences (blue) between the measured and calculated patterns are shown. The vertical markers (black) indicate the Bragg reflections. (Bottom panel) The XRD pattern and Miller indices of the cubic crystal structure of $\mathrm{Ag}_{3} \mathrm{PO}_{4}$ (JCPDS 06-0505) are included for comparison 


\section{Statistics}

Data are presented as the mean \pm SEM. Statistics were performed by Tukey's post hoc test. A $p<0.05$ is considered statistically significant.

\section{Instrumentation}

The structure and morphology of the $\mathrm{Ag}_{3} \mathrm{PO}_{4}$ product were examined by powder X-ray diffraction (XRD; PANalytical X'Pert-PRO MPD) with $\mathrm{Cu} \mathrm{K}_{\alpha}$ radiation and by scanning electron microscopy (SEM; Hitachi S4300), respectively. To examine the antibacterial activities of the $\mathrm{Ag}_{3} \mathrm{PO}_{4}$ product, the growth rates of $E$. coli or P. syringae DC3000 in the absence or presence of $\mathrm{Ag}_{3} \mathrm{PO}_{4}$ without light and in the presence of $\mathrm{Ag}_{3} \mathrm{PO}_{4}$ under blue and red light were determined by measurement of the optical density at $600 \mathrm{~nm}$ with a UV-vis spectrophotometer (X-ma 1200V). A blue LED (NC LED, $\lambda=460 \mathrm{~nm}$ ) and a red LED (NC LED, $\lambda=625 \mathrm{~nm}$ ) with equivalent luminescence were used as the blue and red light sources, respectively.

\section{Results and discussion}

Figure 1a shows an SEM image of the $\mathrm{Ag}_{3} \mathrm{PO}_{4}$ crystals prepared by the precipitation method at room temperature. Most of the $\mathrm{Ag}_{3} \mathrm{PO}_{4}$ crystals exhibit a cubic shape with a size of $1 \mu \mathrm{m}$. Figure $1 \mathrm{~b}$ shows the XRD pattern of the as-synthesized $\mathrm{Ag}_{3} \mathrm{PO}_{4}$ crystals. The Rietveldrefined cell parameters of the $\mathrm{Ag}_{3} \mathrm{PO}_{4}$ crystals in this work are consistent with those of body-centered cubic $\mathrm{Ag}_{3} \mathrm{PO}_{4}$ with $a=0.6013 \mathrm{~nm}$ (JCPDS 06-0505).

Figure $2 \mathrm{a}$ shows the growth rate of $E$. coli in the absence and presence of $\mathrm{Ag}_{3} \mathrm{PO}_{4}$ under dark conditions and in the presence of $\mathrm{Ag}_{3} \mathrm{PO}_{4}$ under red-light $(625 \mathrm{~nm})$ and blue-light $(460 \mathrm{~nm})$ irradiation. In the control experiment without $\mathrm{Ag}_{3} \mathrm{PO}_{4}$ crystals and under dark conditions, the growth rate of $E$. coli increases rapidly during the incubation period of $8 \mathrm{~h}$ and reaches a
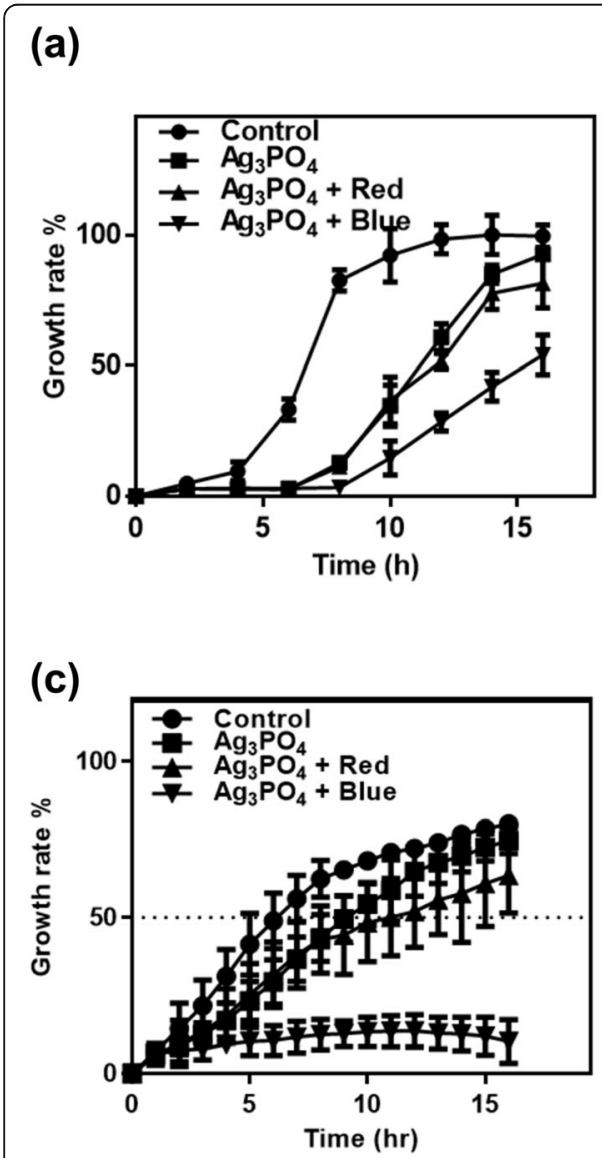

(b)


Fig. 2 a The growth rate of $\mathrm{E}$. coli in the absence (circles) or presence (squares) of $\mathrm{Ag}_{3} \mathrm{PO}_{4}$ under dark conditions and in the presence of $\mathrm{Ag}{ }_{3} \mathrm{PO}_{4}$ under red-light (625 nm, triangles) or blue-light (460 nm, inverted triangles) irradiation. Line graphs represent mean \pm SEM ( $n=3$ ). $\mathbf{b}$ Colony formation of $\mathrm{L}$. innocua in the absence or presence of $\mathrm{Ag}_{3} \mathrm{PO}_{4}$ under dark conditions and in the presence of $\mathrm{Ag}_{3} \mathrm{PO}_{4}$ under red-light or blue-light irradiation. Quantified data are shown in bar graphs (mean \pm SEM; $n=3$ ). Scale bars are $10 \mu m$ in $\mathbf{b}$. $\mathbf{c}$ The growth rate of $P$. syringae DC3000 in the absence (circles) or presence (squares) of $\mathrm{Ag}_{3} \mathrm{PO}_{4}$ under dark conditions and in the presence of $\mathrm{Ag}_{3} \mathrm{PO}_{4}$ under red-light (triangles) or bluelight irradiation (inverted triangles). Line graphs represent mean $\pm \operatorname{SEM}(n=3)$ 
saturation plateau after $12-16 \mathrm{~h}$. The incubation time for growth to $50 \%$ is known as the half-maximal growth time. The half-maximal growth time in the control experiment was $6.5 \mathrm{~h}$ for culturing the $E$. coli in the absence of $\mathrm{Ag}_{3} \mathrm{PO}_{4}$ and under dark conditions. When $\mathrm{Ag}_{3} \mathrm{PO}_{4}$ crystals were present under dark conditions, the growth rate of $E$. coli decreased compared with the growth rate in the control experiment and the halfmaximal growth time increased to $11.0 \mathrm{~h}$. These results indicate that the $\mathrm{Ag}_{3} \mathrm{PO}_{4}$ crystal exhibits antibacterial activity against $E$. coli.

In the presence of $\mathrm{Ag}_{3} \mathrm{PO}_{4}$ crystals and under red-light $(625 \mathrm{~nm})$ irradiation, an $E$. coli growth curve very similar to that for $\mathrm{Ag}_{3} \mathrm{PO}_{4}$ crystals under dark conditions is observed, where the half-maximal growth time is $12.0 \mathrm{~h}$. Because the indirect bandgap energy of crystalline $\mathrm{Ag}_{3} \mathrm{PO}_{4}$ is $2.36 \mathrm{eV}(525 \mathrm{~nm})$, the red light $(625 \mathrm{~nm}, 1.98$ $\mathrm{eV}$ ) lacks sufficient energy to transfer the electron from the valance band to the conduction band of the $\mathrm{Ag}_{3} \mathrm{PO}_{4}$ crystal. This suggests that red light does not induce photoenhancement of the antibacterial activity of $\mathrm{Ag}_{3} \mathrm{PO}_{4}$ crystals. However, under blue-light irradiation $(460 \mathrm{~nm}, 2.70 \mathrm{eV})$, the growth rate of E. coli is substantially decreased in the presence of $\mathrm{Ag}_{3} \mathrm{PO}_{4}$ crystals and the half-maximal growth time is increased to $15.5 \mathrm{~h}$. Because the blue light has sufficient energy to transfer electrons from the valance band to the conduction band of the $\mathrm{Ag}_{3} \mathrm{PO}_{4}$ crystals, the photoinduced enhancement of antibacterial activity of $\mathrm{Ag}_{3} \mathrm{PO}_{4}$ is observed only under blue-light irradiation.

Similar trends were observed for L. innocua, which was used as a surrogate of representative Gram-positive foodborne pathogens, $L$. monocytogenes. Figure $2 \mathrm{~b}$ shows colonies of L. innocua grown on the selective agar plates in the absence and presence of $\mathrm{Ag}_{3} \mathrm{PO}_{4}$ under dark conditions and red-light or blue-light irradiation. $\mathrm{Ag}_{3} \mathrm{PO}_{4}$ decreases the number of $L$. innocua colonies by twofold under dark conditions. The colony number is about $4 /$ $\mathrm{cm}^{2}$ under blue-light irradiation in the presence of $\mathrm{Ag}_{3} \mathrm{PO}_{4}$, when compared to $58 / \mathrm{cm}^{2}$ and $55 / \mathrm{cm}^{2}$ under (a)

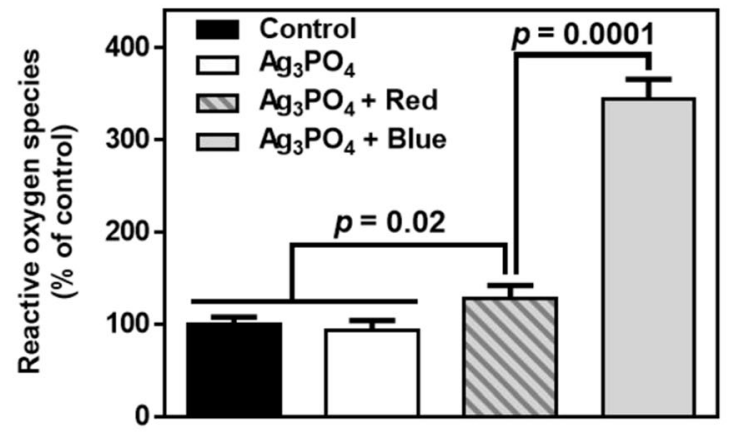

(c)

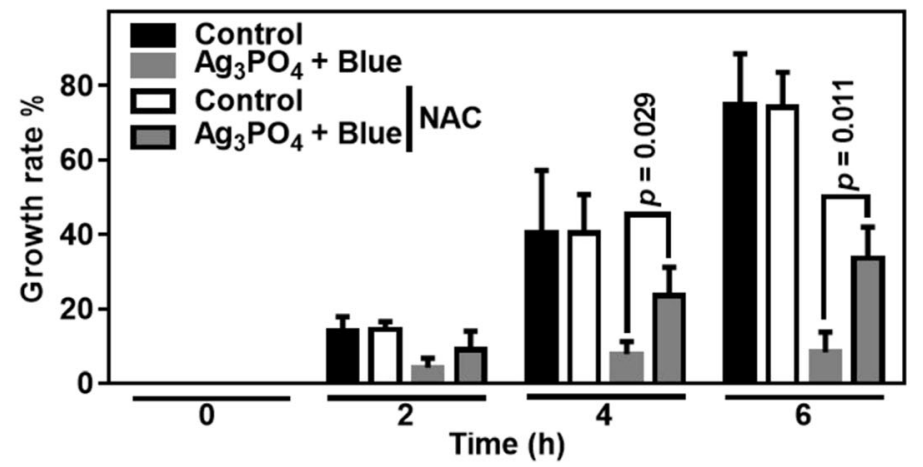

(b)

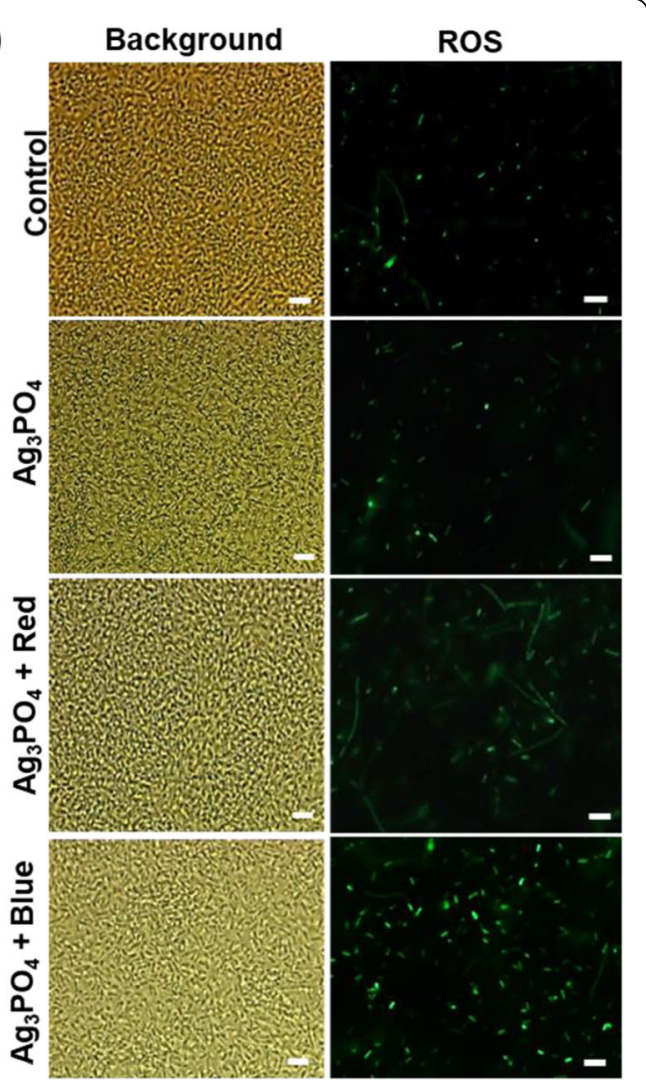

Fig. 3 a The ROS concentration produced in the process of antibacterial action against $E$. coli (mean \pm SEM; $n=3$ ) and $\mathbf{b}$ optic (left panels showing total cells) and fluorescent (right panels) images of E. coli in the absence and presence of $\mathrm{Ag}_{3} \mathrm{PO}_{4}$ under dark conditions and in the presence of $\mathrm{Ag}_{3} \mathrm{PO}_{4}$ under red-light $(625 \mathrm{~nm})$ and blue-light $(460 \mathrm{~nm})$ irradiation. DCFH-DA fluorescent dye was used for ROS detection. Scale bars are $10 \mu \mathrm{m}$ in $\mathbf{b}$. c The growth rate of $E$. coli in the absence or presence of $1 \mathrm{mM}$ N-acetylcysteine (NAC) under dark conditions and in the presence of $\mathrm{Ag}_{3} \mathrm{PO}_{4}$ with or without $1 \mathrm{mM} \mathrm{NAC}$ under blue-light (460 nm, inverted triangles) irradiation. Bar graphs represent mean \pm SEM ( $n=3$ ) 
dark and red-light conditions in the presence of $\mathrm{Ag}_{3} \mathrm{PO}_{4}$, respectively. This result indicates that blue-light irradiation remarkably and synergistically enhances the antibacterial activity of $\mathrm{Ag}_{3} \mathrm{PO}_{4}$. Photoinduced antibacterial activity on the agar plate gives an insight into applications of $\mathrm{Ag}_{3} \mathrm{PO}_{4}$ in anti-fouling and eco-friendly adhesive industry.

We then examined the photoinduced antibacterial activity of $\mathrm{Ag}_{3} \mathrm{PO}_{4}$ against the plant pathogenic P. syringae DC3000 bacterium. In Fig. 2c, the half-maximal growth rates of untreated control and $\mathrm{Ag}_{3} \mathrm{PO}_{4}$ under dark conditions are $6 \mathrm{~h}$ and $9 \mathrm{~h}$, respectively. Comparatively, the half-maximal growth rates of $\mathrm{Ag}_{3} \mathrm{PO}_{4}$ under red-light and blue-light irradiations are $11 \mathrm{~h}$ and undetectable (caused by almost complete inhibition), respectively. Accordingly, $\mathrm{Ag}_{3} \mathrm{PO}_{4}$ under blue-light irradiation almost completely inhibits the growth of $P$. syringae DC3000, suggesting that $\mathrm{Ag}_{3} \mathrm{PO}_{4}$ under blue-light irradiation can be useful for crop protection from phytopathogenic bacteria.
To understand the mechanisms underlying the antibacterial activity of $\mathrm{Ag}_{3} \mathrm{PO}_{4}$ crystals, we examined whether $\mathrm{Ag}_{3} \mathrm{PO}_{4}$ crystals alter the levels of ROS in $E$. coli. Interestingly, $\mathrm{Ag}_{3} \mathrm{PO}_{4}$ crystals appeared to increase the level of ROS under blue-light irradiation, whereas $\mathrm{Ag}_{3} \mathrm{PO}_{4}$ crystals alone or under red light exhibited no effect, as shown in Fig. 3. Quantified amounts of ROS and ROS-stained E. coli cells are shown in Fig. $3 \mathrm{a}$ and b, respectively. In both panels, the level of ROS was highest in $E$. coli cells exposed to $\mathrm{Ag}_{3} \mathrm{PO}_{4}$ crystals in conjunction with blue-light irradiation. These data indicate that the antibacterial activity of $\mathrm{Ag}_{3} \mathrm{PO}_{4}$ under blue-light irradiation corresponds to the amount of ROS in E. coli. More convincingly, $\mathrm{N}$-acetylcysteine (NAC) known as an ROS scavenger reverses the antibacterial activity of $\mathrm{Ag}_{3} \mathrm{PO}_{4}$ under blue-light irradiation as shown in Fig. 3c.

We furthermore examined the antiviral activity of $\mathrm{Ag}_{3} \mathrm{PO}_{4}$ under blue-light irradiation. Figure 4a shows that amphotropic 10A1 murine leukemia virus (MLV)

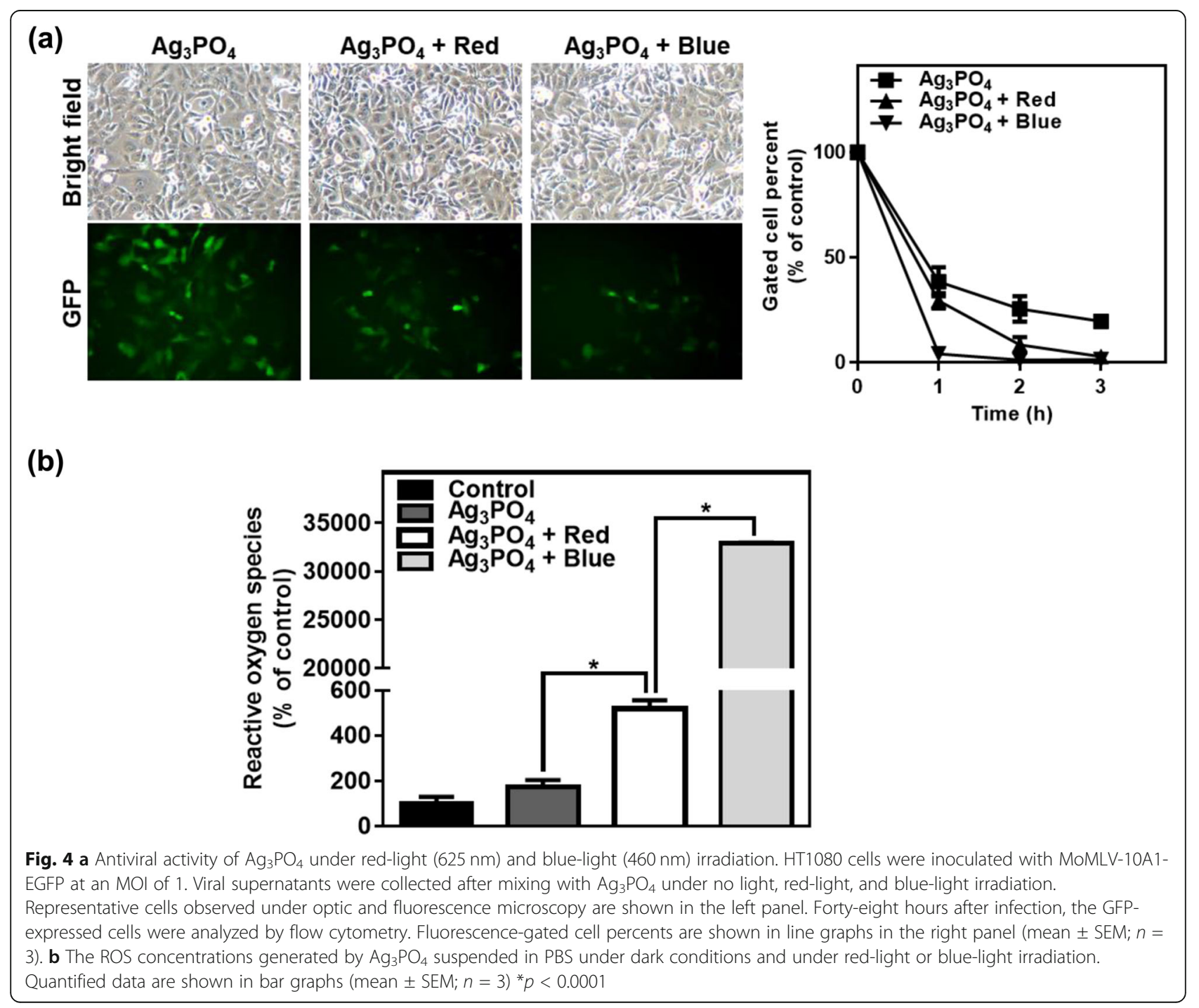


was more severely inactivated by $\mathrm{Ag}_{3} \mathrm{PO}_{4}$ under bluelight irradiation, when compared to $\mathrm{Ag}_{3} \mathrm{PO}_{4}$ under dark conditions and $\mathrm{Ag}_{3} \mathrm{PO}_{4}$ under red-light irradiation. We assume that inactivation of the MLV by blue-light irradiated $\mathrm{Ag}_{3} \mathrm{PO}_{4}$ might be attributable to the peroxidation of the envelope membrane phospholipids, which is furthermore detrimental to DNA (Paiva and Bozza 2014). Given that the envelop membrane phospholids are damaged by blue-light irradiated $\mathrm{Ag}_{3} \mathrm{PO}_{4}$, other enveloped viruses including HIV-1, SARS-CoV, MERS-CoV, and SARS-CoV2 can be inactivated by blue-light irradiated $\mathrm{Ag}_{3} \mathrm{PO}_{4}$. To understand the antiviral activity of $\mathrm{Ag}_{3} \mathrm{PO}_{4}$ under blue-light irradiation, the possibility of the generation of ROS was examined when blue light irradiates on the $\mathrm{Ag}_{3} \mathrm{PO}_{4}$ solution. Figure $4 \mathrm{~b}$ shows that ROS is substantially increased by photoinduction to the $\mathrm{Ag}_{3} \mathrm{PO}_{4}$ solution. This result supports that the ROS is detrimental to viral particles.

\section{Conclusion}

We synthesized cubic $\mathrm{Ag}_{3} \mathrm{PO}_{4}$ crystals with a mean size of $1 \mu \mathrm{m}$ to investigate their antibacterial and antiviral activities. The $\mathrm{Ag}_{3} \mathrm{PO}_{4}$ crystals showed good antibacterial and antiviral activities against E. coli, L. innocua, P. syringae DC3000, and amphotropic 10A1 MLV. The photoinduced enhancement of the antibacterial and antiviral activities of $\mathrm{Ag}_{3} \mathrm{PO}_{4}$ under blue-light irradiation was observed. The ROS mediation process in the antibacterial and antiviral activities was confirmed through measurements of the concentrations of ROS. The formation of ROS plays an important role in the antibacterial and antiviral activities of $\mathrm{Ag}_{3} \mathrm{PO}_{4}$. These findings suggest that the photoinduced enhancement of antibacterial and antiviral activities of $\mathrm{Ag}_{3} \mathrm{PO}_{4}$ can be used for the biomedical application including anti-fouling, additives, and crop cultivations.

\footnotetext{
Abbreviations

DCFH-DA: 2',7'-Dichlorodihydrofluorescein diacetate; E. coli: Escherichia coli; EGFP: Enhanced green fluorescent protein; GFP: Green fluorescent protein; L. innocua: Listeria innocua; LB: Luria-Bertani; MLV: Murine leukemia virus; MOI: Multiplicity of infection; NAC: N-Acetylcysteine; OAB: Oxford agar base; PBS: Phosphate-buffered saline; P. syringae: Pseudomonas syringae; ROS: Reactive oxygen species; SEM: Scanning electron microscopy; TEA: Triethanolamine; TSA: Tryptic soy agar; TSB: Tryptic soy broth; XRD: X-ray diffraction
}

\section{Acknowledgements}

The authors acknowledge financial support from the National Research Foundation of Korea (NRF-2018R1D1A1B07040714).

\section{Authors' contributions}

All authors have equal contribution to this research work. The author(s) read and approved the final manuscript.

\section{Funding}

National Research Foundation of Korea (NRF-2018R1D1A1B07040714)

Availability of data and materials

Not applicable

\section{Competing interests}

The authors declare that they have no competing interests.

\section{Author details}

'Department of Molecular Biology, Dankook University, Cheonan 31116, Republic of Korea. ${ }^{2}$ Department of Food Engineering, Dankook University, Cheonan 31116, Republic of Korea. ${ }^{3}$ Department of Microbiology, Dankook University, Cheonan 31116, Republic of Korea. ${ }^{4}$ Department of Chemistry, Dankook University, Cheonan 31116, Republic of Korea.

Received: 16 April 2020 Accepted: 5 June 2020

Published online: 11 June 2020

\section{References}

$\mathrm{Bi}$ Y, Ouyang S, Cao J, Ye J. Facile synthesis of rhombic dodecahedral AgX/ $\mathrm{Ag}_{3} \mathrm{PO}_{4}(\mathrm{X}=\mathrm{Cl}, \mathrm{Br}, \mathrm{I})$ heterocrystals with enhanced photocatalytic properties and stabilities. Phys Chem Chem Phys. 2011;13:10071-5.

Buckley JJ, Lee AF, Olivic L, Wilson K. Hydroxyapatite supported antibacterial $\mathrm{Ag}_{3} \mathrm{PO}_{4}$ nanoparticles. J Mater Chem. 2010;20:8056-63.

Chatterjee D, Dasgupta S. Visible light induced photocatalytic degradation of organic pollutants. J Photochem. Photobiol C: Photochem Rev. 2005;6:186205.

Chen $X$, Dai Y, Wang X. Methods and mechanism for improvement of photocatalytic activity and stability of $\mathrm{Ag}_{3} \mathrm{PO}_{4}$ : a review. J Alloys Compd. 2015;649:910-32.

Dickinson BC, Chang CJ. Chemistry and biology of reactive oxygen species in signaling or stress responses. Nat Chem Biol. 2011;7:504-11.

Dong L, Wang P, Wang S, Lei P, Wang Y. A simple way for $\mathrm{Ag}_{3} \mathrm{PO}_{4}$ tetrahedron and tetrapod microcrystals with high visible-light-responsive activity. Mater Lett. 2014;134:158-61.

Du J, Gebicki JM. Proteins are major initial cell targets of hydroxyl free radicals. Int J Biochem Cell Biol. 2004;36:2334-43.

Lapworth DJ, Baran N, Stuart ME, Ward RS. Emerging organic contaminants in groundwater: a review of sources, fate and occurrence. Environ Pollut. 2012; 163:287-303.

Li Y, Zhang W, Niu J, Chen Y. Mechanism of photogenerated reactive oxygen species and correlation with the antibacterial properties of engineered metal-oxide nanoparticles. ACS Nano. 2012;6:5164-73.

Liang Q, Ma W, Shi Y, Li Z, Yang X. Hierarchical $\mathrm{Ag}_{3} \mathrm{PO}_{4}$ porous microcubes with enhanced photocatalytic properties synthesized with the assistance of trisodium citrate. CrystEngComm. 2012;14:2966-73.

Mouele ESM, Tijani JO, Fatoba OO, Petrik LF. Degradation of organic pollutants and microorganisms from wastewater using different dielectric barrier discharge configurations-a critical review. Environ Sci Pollut Res. 2015;22: 18345-62.

Overmyer K, Brosché M, Kangasjärvi J. Reactive oxygen species and hormonal control of cell death. Trends Plant Sci. 2003;8:335-42.

Paiva CN, Bozza MT. Are reactive oxygen species always detrimental to pathogens? Antiox Redox Signal. 2014;20:1000-37.

Piccirillo C, Pinto RA, Tobaldi DM, Pullar RC, Labrincha JA, Pintado MME, Castro PML. Light induced antibacterial activity and photocatalytic properties of Ag/ $\mathrm{Ag}_{3} \mathrm{PO}_{4}$-based material of marine origin. J Photochem Photobiol A: Chem. 2015;296:40-7.

Schwarzenbach RP, Escher BI, Fenner K, Hofstetter TB, Johnson CA, Gunten UV, Wehrli B. The challenge of micropollutants in aquatic systems. Science. 2006; 313:1072-7.

Seo Y, Yeo BE, Cho YS, Park H, Kwon C, Huh YD. Photo-enhanced antibacterial activity of $\mathrm{Ag}_{3} \mathrm{PO}_{4}$. Mater Lett. 2017;197:146-9.

Suwanprateeb J, Thammarakcharoen F, Wasoontararat K, Chokevivat W, Phanphiriya P. Preparation and characterization of nanosized silver phosphate loaded hydroxyapatite by single step co-conversion process. Mater Sci Eng C. 2012;32:2122-8.

Wu A, Tian C, Chang W, Hong Y, Zhang Q, Qu Y, Fu H. Morphology-controlled synthesis of $\mathrm{Ag}_{3} \mathrm{PO}_{4}$ nano/microcrystals and their antibacterial properties. Mater Res Bull. 2013;48:3043-8.

\section{Publisher's Note}

Springer Nature remains neutral with regard to jurisdictional claims in published maps and institutional affiliations. 